\title{
El debate arquitectónico en Barcelona en las postrimerías del franquismo
}

The Architectural Debate in Barcelona at the End of the Franco Era

Le débat architectural à Barcelone à la fin du franquisme

\section{Antonio Pizza}

\section{OpenEdition}

\section{Journals}

Edición electrónica

URL: http://journals.openedition.org/rccs/4173

DOI: $10.4000 /$ rccs. 4173

ISSN: 2182-7435

Editor

Centro de Estudos Sociais da Universidade de Coimbra

Edición impresa

Fecha de publicación: 1 diciembre 2010

Paginación: 107-117

ISSN: 0254-1106

Referencia electrónica

Antonio Pizza, «El debate arquitectónico en Barcelona en las postrimerías del franquismo », Revista Crítica de Ciências Sociais [En línea], 91 | 2010, Puesto en línea el 16 octubre 2012, consultado el 30 abril 2019. URL : http://journals.openedition.org/rccs/4173; DOI : 10.4000/rccs.4173 


\section{ANTONIO PIZZA}

\section{El debate arquitectónico en Barcelona en las postrimerías del franquismo}

El artículo analiza el debate arquitectónico desarrollado en Barcelona en los últimos años de vigencia del régimen franquista, intentando evidenciar las posiciones defendidas por los diferentes protagonistas y sus relaciones con las cuestiones afrontadas en el panorama internacional. Asimismo, se tiene en cuenta que en este contexto cualquier reivindicación cultural se convertía inevitablemente en contestación de lo existente.

Palabras clave: arquitectura; Barcelona; ciudades; "Escuela de Barcelona"; realismo; urbanismo; 1960-1970.

Palavras-chave: arquitectura; Barcelona; cidades; "Escola de Barcelona"; realismo; urbanismo; 1960-1970.

Hacia el final de los años cincuenta en Cataluña, la única actividad de grupo que en cierta manera había logrado mantener viva una relativa continuidad con los postulados de la modernidad internacional (el así llamado "Grup R") se iba extinguiendo, agotando sus propósitos básicos de fomentar un debate, entre los profesionales de la arquitectura, alternativo al oscurantismo imperante en las instituciones académicas y corporativas del régimen franquista.

Los paulatinos cambios en el contexto socio-político parecían exigir en el ambiente arquitectónico nuevas estructuras o plataformas de debate capaces de promover la reflexión sobre el futuro disciplinar que continuaba languideciendo, mientras el territorio era sometido a una urbanización salvaje e indiscriminada.

\section{“Pequeños Congresos" y realismo arquitectónico}

En 1959, con el número de noviembre-diciembre, comienzan las colaboraciones de Oriol Bohigas en Serra d'Or; el 14, 15 y 16 del mismo mes se desarrolla en Madrid el Primer Pequeño Congreso, abriendo un inédito terreno de contacto y confrontación entre el mundo profesional de la 

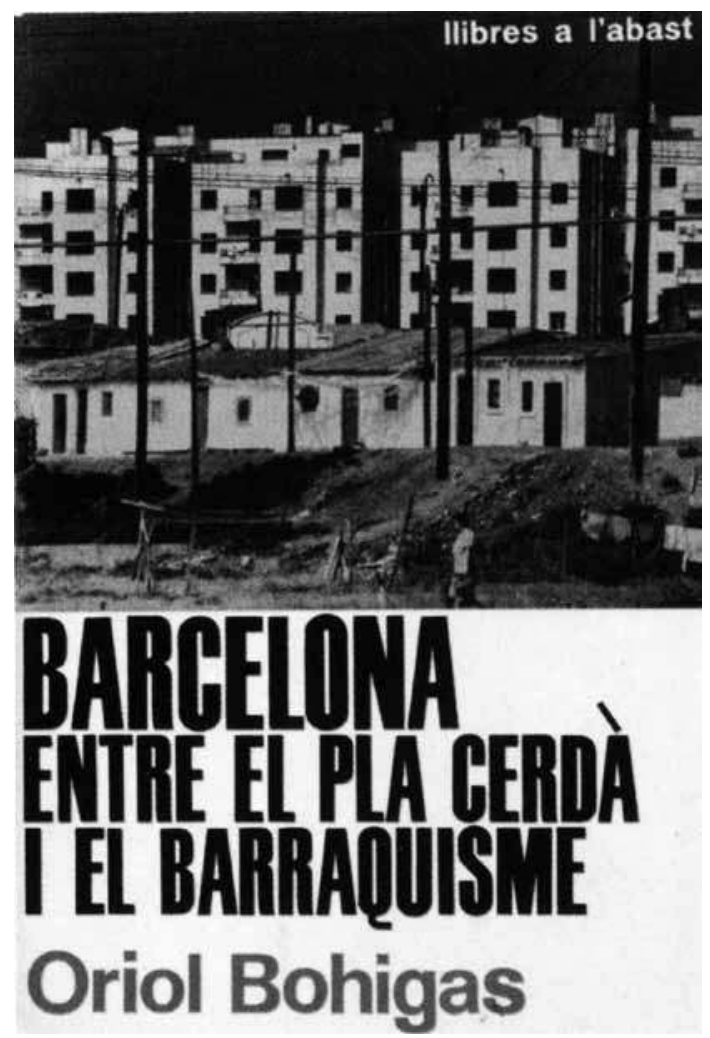

Oriol Bohigas (1963), Barcelona entre pla Cerdà i el Barraquisme. Barcelona, Edicions 62

capital -impulsado por la incansable actividad organizadora de Carlos de Miguel- y el de Barcelona, en el que va asumiendo gradualmente su papel de agitador cultural Oriol Bohigas.

Simultáneamente, una acepción realista de la obra de arte parece aflorar en las distintas formas de la representación, con más o menos éxito y será verificable también en la literatura contemporánea, en las novelas de Juan Goytisolo (La resaca, 1958), de Juan García Hortelano (Nuevas amistades, 1959) o de Antonio Ferres (La piqueta, 1959). En 1960, Josep Maria Castellet publica la antología Veinte años de poesía española (Castellet, 1960) que servirá para legitimar la generación poética de Carlos Barral, Jaime Gil de Biedma y José Agustín Goytisolo.

Y precisamente en relación con estos escritores se comenzará a aplicar la afortunada etiqueta de "Escuela de Barcelona" (usada con cierta regularidad en las publicaciones a partir de 1962), con el objetivo de connotar 
una búsqueda en la que a menudo el ambiente urbano se convertirá en una referencia prioritaria, donde será privilegiado el tono coloquial del lenguaje lírico con intencionalidad claramente antirretórica, y sin eludir jamás el fundamental y constitutivo planteamiento crítico respecto de la situación política española.

Esbozando los aspectos comunes de esta generación literaria, Carme Riera enumera un conjunto de características que pueden resultar altamente iluminadoras si pensamos en el posterior intento de institucionalizar una "Escuela de Barcelona" de sesgo arquitectónico:

[...] los inicios conversacionales, la andadura narrativa del poema, un abundante uso de la repetición y la comparación [...]. Con el empleo de la repetición, sin duda, los poetas comprometidos intentaban asegurar la comprensión de su mensaje por la 'inmensa mayoría' a quien se dirigían, a la vez que conectaban con prácticas literarias rudimentarias próximas a la canción popular folklórica o incluso a las letanías. (Riera, 1988: 265)

En el conjunto de la cultura progresista, en definitiva, se asiste en estos años a una postura que tiende a sublimar no sólo la atávica discordia entre "arte" y "vida", sino también aquella entre formas y manifestaciones "altas" y "bajas" del saber. Por lo tanto, será programática la voluntad de acercamiento a lo que se considera ser el patrimonio despreciado de las masas populares, en busca de una recuperación y rescate de estas modalidades expresivas, pero también de una resignificación del papel del intelectual en la sociedad. Una posición empapada de ribetes éticos, quizá más que escrupulosamente políticos -no por casualidad, es el momento en que en el sector artístico-arquitectónico resurge el magisterio de William Morris, dirigido a tejer una relación fáctica entre arte y sociedad, en la que el acto proyectual asumiría un valor fundamentalmente educativo.

En este contexto, Bohigas sostiene que deberá ser la realidad actual, con todos sus dramas imperiosos, la que constituya el punto de partida de cualquier nueva y "auténtica” investigación arquitectónica. Desde la óptica de una toma de conciencia de las implicaciones políticas de la actividad profesional, en la que una elección entre "urbanismo capitalista" o "urbanismo socialista" se vuelve impostergable, el autor precisa su polémica y defiende, paradójicamente, las positividades sociales experimentables en las barracas (Bohigas, 1957) frente a la alienación connatural a la edificación periférica especulativa, reivindicando, al mismo tiempo, el valor de los materiales tradicionales (Bohigas, 1960), vistos como la única solución operativa en un país absolutamente retrasado en el desarrollo de las tecnologías constructivas. 
Bohigas, además, publica en 1962 un texto fundacional (explícito ya desde el título, Cap a una arquitectura realista, en el que se parafrasea el famoso libelo lecorbuseriano Vers une architecture), donde se expone adecuadamente un programa que, con ansia reduccionista, anhela rescatar las virtudes ya sepultadas de una disciplina corrompida:

Una vez fundamentado el lenguaje del nuevo estilo, lo que hay que exigir a cada arquitecto es que precisamente evite las goteras, que se ajuste a las realidades tecnológicas y sociales del país y del momento, que haga una obra para ser habitada por un determinado grupo de hombres y que tenga la humildad de no proclamar diariamente muchas trascendencias. (Bohigas, 1962: 18)

Comenzando por estos primeros esbozos de una poética reivindicativa, el principal vehículo de transformación arquitectónica y social deviene, pues, el universo referencial abarcado en el polimorfo concepto de "realismo". Naturalmente, detrás de esta identidad terminológica existe el deseo del intelectual de ensayar el reflejo taumatúrgico en una coralidad de la que se siente ya desligado; la llamada operativa al bagaje de las "tradiciones populares" debería ofrecer la ilusión de la atemporalidad al proyecto contemporáneo, anulando la intrusión rupturista de las lógicas de lo nuevo, de lo moderno, de la trasgresión aparentemente fin de sí misma.

El intento de superación de la ya consolidada separación entre masas y "alta" cultura, enfatiza además una exigencia: la de reabrir los interrumpidos canales de comunicación con los potenciales usuarios de una propuesta salida del mundo de la representación, conjugando términos comprensibles como tierra, tradición, valores imperecederos. Se delinea así un ámbito cognoscitivo que por principio aspira a derrocar los presupuestos de un comportamiento de contestación radical, y no parecería muy plausible hacer interactuar "realismo" y "vanguardia"; sin embargo, es justo esto lo que será paradójicamente intentado por las fuerzas locales, en la acepción inicialmente contradictoria de un "realismo de vanguardia".

Se perfila además un predominio de las poéticas de la "figuración" que cristalizarán en las formas de la redundancia, de la superabundancia de los detalles informativos, de la hipotiposis; una tendencia destacada, en definitiva, hacia la hipercomunicación, sostenida por un planteamiento retórico que mantiene como objetivo prioritario el logro de un elevado nivel de transmisión de los propios contenidos, sobre todo respecto a lo que hasta el momento permanecía excluido de tal capacidad de intercambio mediático.

No muy diferente había sido la estrategia cultural actuante en Italia unos pocos años antes, inmediatamente después de la segunda guerra mundial y la 
sucesiva Liberazione; nos referimos, obviamente, a la explosión de poéticas neorrealistas (desde el cine a la literatura, del arte a la arquitectura), reflejo explícito de una necesidad de hablar con un lenguaje inmediatamente. Un país salido de una catástrofe de desastrosas consecuencias se ve así envuelto en una verdadera y auténtica "urgencia por decir"; imperativo moral que se traduce, en literatura, en la valorización de la narratividad (incluso oral), de la fidelidad al documento, de la necesaria adherencia a las cosas.

\section{Reflexiones lingüísticas y la "Escuela de Barcelona"}

En 1967, una de las primeras iniciativas emprendidas por la neonata escuela de diseño EINA fue la de convocar una reunión clandestina (3/5-2-1967) con un grupo de intelectuales italianos, el "Gruppo 63", compuesto por 25 autores de extracción prevaleciente literaria, entre los que se encontraban: Umberto Eco, ${ }^{1}$ Nanni Balestrini, Renato Barilli, Furio Colombo, Gillo Dorfles, Giorgio Manganelli, Vittorio Gregotti, mientras en la representación local, de composición mucho más heterogénea, estaban Carlos Barral, Josep Maria Castellet, Jaime Gil de Biedma, Gabriel Ferrater, José Agustín Goytisolo, Salvador Clotas, Alexandre Cirici, Antoni Tàpies, Albert Ràfols Casamada, Ramon Gubern, Ricardo Bofill, Oscar Tusquets, Federico Correa, Lluís Domènech, Oriol Bohigas.

Más allá de las cuestiones de orden general, hay que señalar que el grueso de las discusiones giraron en torno a cuestiones pertinentes a una interpretación "lingüística" de la obra, dado que el grupo proveniente de la escuela Elisava se mostraba bastante receptivo hacia la semiótica y la teoría de la información, o a la aplicación de las teorías del estructuralismo en el terreno de la estética, del arte y de la proyectualidad humana.

Mientras tanto, el anteriormente válido aserto disciplinar "progresista", basado en el concepto de realismo, comienza a tambalearse: en un artículo sobre los premios FAD (Fomento de las Artes Decorativas) de 1966 (galardón de gran prestigio profesional, otorgado desde 1958 a las mejores obras de un año), Oscar Tusquets señala el significativo retorno a un terreno más disciplinar, evidenciando una actitud generacional que intenta hacer arquitectura sólo a través del recurso a aquellos que pueden ser considerados los instrumentos específicos de la actividad proyectual. Precisamente

\footnotetext{
${ }^{1}$ De Eco ya había sido traducida al español Opera Aperta (Seix Barral, 1965); además, el autor había dictado una conferencia en el Colegio Oficial de Arquitectos de Barcelona (COACB) el mismo año ("La obra abierta en el arte contemporáneo") y otra, siempre en el COACB, el 9-5-1966. En esta segunda parte de la década, Eco, estará presente en el COACB el 1-2-1969 con la conferencia: "Semiologia dell'Architettura", y en la inauguración de la exposición "Los comics de ciencia ficción en Barcelona" (3-2 / 8-2-1969; COACB).
} 
el surgimiento de tales indicios llevará al autor a prefigurar una suerte de "Escuela de Barcelona" -contrapuesta al clima menos estimulante de Madrid (Tusquets, 1967: 67) - que encontrará entre sus parámetros principales la comunidad literaria existente, así como la contemporánea "Escuela de Barcelona” cinematográfica, formalizada entre 1967 y 1968.

Vale la pena subrayar que las características generales de esta escuela, más allá del obvio rechazo político del régimen y de una voluntad innovadora en la expresividad fílmica, serían:

1) Autofinanciación y sistema cooperativo de producción. 2) Trabajo en equipo [...]

3) Preocupación preponderantemente formal [...] 4) Carácter experimental y vanguardista 5) Subjetividad [...] 6) Personajes y situaciones ajenas a los del cine de Madrid 7) Utilización de actores no profesionales 8) Producción realizada de espaldas a la distribución 9) Salvo escasas excepciones, formación no académica ni profesional de los realizadores". (Jordá, 1967 apud Riambau e Torreiro, 1999: 168-169)²

Será de nuevo Bohigas quien se preocupará de legitimar rápidamente este esfuerzo de catalogación en dos breves intervenciones del año 1968; en concreto, en el segundo artículo, la obra condecorada por el premio FAD de 1968 (la "Residencia Mare Güell, de Lluís Cantallops y Jaume Rodrigo) será considerada como una suerte de realización ejemplar de la arquitectura comprometida catalana:

Todo responde al esfuerzo de determinación lógica de la forma a partir de las funciones y, sobre todo, aceptando los auténticos procesos tecnológicos, siempre adecuados a la realidad modesta e inmediata, sin menospreciarla y hasta manteniendo un gusto por las tradiciones muy arraigadas [...] Es sorprendente comprobar, por ejemplo, cómo se emparenta formalmente con el Colegio de les Teresianas de Gaudí, y con las obras de ladrillo de Domènech i Montaner. (Bohigas, 1968: 50)

Auténtica contribución fundacional será, sin embargo, el texto "Una posible 'Escuela de Barcelona'”, aparecido en el número 118 (1968) de la revista Arquitectura, en el que Bohigas enumera las hipotéticas características comunes del grupo: 1) "la naturaleza y procedencia de los encargos";

\footnotetext{
${ }^{2}$ Bofill participó en la "agitación" cinematográfica, produciendo dos películas: Circles (1966) e Schizo (1970), ambas con la colaboración de S. Vergano. Entre las películas más representativas de esta "escuela": Brillante porvenir (R. Gubern, V. Aranda; 1963), Los felices sesenta (J. Camino; 1963), Fata Morgana (V. Aranda; 1965), Noche de vino tinto (J. M. Nunes; 1966), Dante no es únicamente severo (J. Esteva, J. Jordà; 1967), Tuset Street (L. Marquina; 1968), Nocturno 29 (P. Portabella; 1968).
} 
2) "la voluntaria, consciente y culta adecuación a estas realidades modestas"; 3) "El seguimiento muy firme de la dicción más exigentemente racionalista"; 4) "El intento de romper hasta el máximo los códigos establecidos" (siguiendo -como declara el propio autor- las indicaciones teóricas de Umberto Eco); 5) "el pesimismo"; 6) "un cierto gusto por las actitudes críticas, irónicas, básicamente inseguras, ambiguas y, hasta nos atreveríamos a decir, francamente cínicas"; 7) "El elogio del escándalo como revulsivo y la llamada frivolidad como actitud crítica y pesimista"; 8) "Una cierta posición cultural"; 9) "La coherencia de estilo formal" (Bohigas, 1969: 24-30).

En todo caso, el escrito tiende más al reconocimiento de formas de vida compartida, que a la adscripción de determinadas opciones disciplinarias; $y$, no por casualidad, serán estos los años en que una auténtica boutade se convierte en una etiqueta de identidad. Al parecer, todo nació de una intervención periodística de Joan de Sagarra -en una de sus "rumbes" publicadas en Tele/eXpres-, quien utilizó el término gauche divine para distinguir un grupo de representantes de la cultura autóctona, en gran mayoría profesionales liberales, unificados por un estilo de vida en franca oposición a las convenciones del régimen y que intentaban practicar, en los límites de lo posible, momentos de libertad y transgresión. De hecho, lo explotaron tanto los que pretendían a toda costa "reconocerse" como los que querían, a su vez, ver bien claro quién era el enemigo a combatir, y a qué se dedicaba. En realidad, la ausencia de un verdadero y real nexo, de una efectiva coherencia ideológica, impedirá la decantación de una crítica radical y efectiva de lo existente.

La gauche divine fue más que una forma de pensar, una forma de mirar, un punto de partida y de ruptura que cada cual estableció en una fecha y en un lugar acorde con su propia biografía. (Règas, 2000: 15-16)

He hablado de ciertas afinidades culturales y políticas. Preciso ahora que eran difusas y sutiles, más próximas a la actitud que a las ideas y a la acción. (Miserachs, 1998: 136)

Y Vázquez Montalbán volviendo “a posteriori” sobre el tema afirmará:

A los que se nos colgó el sambenito de la 'gauche divine' no éramos más que jóvenes profesionales de la cultura imbuidos del dogmatismo del antidogmatismo y del esquematismo del antiesquematismo. Sólo nos unía la evidencia de que se vive solamente una vez y hay que aprender a querer y a vivir. (Montalbán, 1974: 13)

\footnotetext{
3 Sobre el tema volverá también Rafael Moneo, "La llamada Escuela de Barcelona", Arquitectura, 121, Madrid 1969.
} 
En el artículo antes citado de Bohigas, un examen elemental de las categorías propuestas difícilmente podría llevar a identificar en este conjunto heterogéneo los nexos de unión de tipo disciplinar. Como rasgo unificador de tal escuela, de hecho, en repetidas ocasiones ha sido enfocado el recurso a una concepción estrictamente "volumétrica" de las construcciones, con una abundancia de los llenos sobre los vacíos y donde incluso los elementos de decoración (bancos, farolas, mamparas) son a menudo resueltos con muros macizos, prestando una gran atención a las entregas y a los detalles en general, con una preferencia expresiva por los materiales pobres. El énfasis puesto en los sistemas agregativos de los componentes arquitectónicos llevaría, además, a una valorización del proceso ejecutivo, de la "factura" de los elementos, así como de la textura de las partes y de su dialéctica; y la insistencia sobre la procesualidad del hacerse, pues, se convierte también en inevitable aplauso a una mentalidad laboral estrictamente artesanal.

Permanece evidente, no obstante, una interpretación de la arquitectura que se concentra exclusivamente en el objeto, prescindiendo de cualquier consideración de tipo urbano, con el riesgo que tal obsesión por los detalles, por las soluciones miniaturizadas, se transforme en un ejercicio manierista sobre la propia pobreza de los medios representativos disponibles, mientras la ciudad contemporánea sigue desarrollándose de manera descontrolada y especulativa. Sin contar luego con la frustrante inefectividad respecto a la pretendida transformación de la sociedad, de la cual estas realizaciones deberían ser, al menos, un testimonio.

Siguiendo las indicaciones presentes en algunos ensayos de Eco -principalmente Opera Aperta (1962) y La Struttura Assente (1968)- también la arquitectura, pese a su prevaleciente cualidad funcional, será analizada como hecho comunicativo, como fenómeno que se articula según las dobles valencias de "significante" y "significado", con las llamadas funciones connotantes destinadas a revestir un peso de primer plano en las transmisiones mediáticas del lenguaje proyectual.

Hacia el final de la década, pues, se confirmarán las tendencias que delinean para la arquitectura un terreno de identidad integralmente autógeno y orientado a la experimentación lingüística, en el cual las opciones temáticas se convierten en absolutamente secundarias para la identificación de una proyección crítica respecto del sistema:

La arquitectura no resolverá el problema de la vivienda, ni resolverá la sociedad aplicándose a trabajar intensamente en los suburbios. [...] Lo que puede hacer la arquitectura es trabajar en su propio campo: subrayar en su lenguaje las contradicciones y las estafas planteadas en la sociedad del consumo. (Bohigas, 1969a: 13) 


\section{Anhelos de vanguardia entre sugestiones "pop"}

En 1969, Bohigas publica Contra una arquitectura adjetivada, central contribución a la irrenunciable identificación de parámetros de actualidad; texto en el que se puede señalar - entre otros - la influencia ejercida por la reflexión teórica de Vittorio Gregotti, quien publicaba en 1966 su importante estudio: Il territorio dell'architettura.

En realidad, se trata de una excesiva adjetivación de la arquitectura. O se la considera válida sólo en cuanto viene definida por la aplicación prioritaria de unos adjetivos -de carácter tecnológico, temático, metodológico, realista, etc...- o se la convierte en un puro hecho adjetivo de otras realidades sustantivas -de carácter político, social, profesional, etc... Es decir, o se la condiciona a los adjetivos, o se la convierte en adjetivo, sin consideraciones válidas sobre su propia sustantividad. (Bohigas, 1969b: 7-8)

La interiorización de tales actitudes debería conducir a una formulación "vanguardista" de la profesión, válida para llevar a cabo una crítica demoledora hacia un presente no compartido. Pero ¿qué cosa pueden querer significar tales convicciones en términos rigurosamente arquitectónicos? $¿$ Nos encontramos frente a un complaciente guiño a las tesis venturianas, a la capacidad revolucionaria de la ironía o del contrasentido? Y la defensa del "absoluto progresismo del lenguaje", ¿a qué debería llevar en la concreción de una configuración formal?

En 1970, Lluís Clotet publica un breve artículo - "En Barcelona: por una arquitectura de la evocación”- en el que, casi a la manera de un manifiesto, se vuelven a proponer temas ya discutidos:

\footnotetext{
Alejados del optimismo de una posible incidencia positiva y directa, nos atraen las posibilidades de una arquitectura que pretenda denunciar aquello que difícilmente puede cambiar [...]. Por un lado la voluntad de apurar al máximo la 'racionalidad posible' y por otro la denuncia de las limitaciones de todo orden que no han consentido incrementarla. [...] Sus obras pretenden ser una invitación a la reflexión sobre el entorno en el que se realizan. (Clotet, 1970: 108)
}

Este "manifiesto" fue leído en 1970 durante un encuentro en La Garriga, organizado por el estudio PER (fundado en 1964 por Lluís Clotet, Oscar Tusquets, Pep Bonet y Cristian Cirici), en el que participaron un importante número de arquitectos españoles y portugueses. El encuentro fue organizado por B. de Moura, que así lo presenta en una carta del 25-1-1970: 
Se trataría de hablar durante este encuentro de la experiencia concreta del trabajo personal del arquitecto, de las posibilidades que cada uno ha descubierto en la utilización del lenguaje arquitectónico con relación al favorecimiento de un cambio en el orden de los valores establecidos. [...] Ponemos un énfasis especial en que el análisis de las posibilidades de favorecer un cambio se limiten al lenguaje arquitectónico, precisamente porque es donde difícilmente se ven esas posibilidades. ${ }^{4}$ (Moura, 1970)

El congreso se centró, pues, en reflexiones que deban prioridad a las cuestiones "lingüísticas", y mereció un lúcido comentario crítico por Manuel Vázquez Montalbán:

La eficacia de ese lenguaje para destruir el mecanismo mismo de la ley de oferta y demanda no se ha revelado, ni parece coherente que una clase social, capaz de crear mecanismos de defensa contra lenguajes más contundentes, pueda sentirse afectada por díscolas construcciones que dicen no. Incluso aquellas construcciones 'de protesta' que menos alardes asimilables se permiten, apenas sí inciden sobre una minoría sensibilizada por la cuestión. (Montalbán, 1970: 16)

En términos generales, sin embargo, en torno a 1968, se hace explícita la intención de tomar distancia con la "Escuela de Barcelona" por parte de las generaciones más jóvenes, atraídas por los modelos de vida norteamericanos y por las elaboraciones teóricas de Robert Venturi. Las reflexiones de este arquitecto ejercerán una notable influencia sobre una sensibilidad contemporánea proyectada hacia la sustitución de orientaciones consideradas como anticuadas o excesivamente dogmáticas, respecto de las cuales lo que provenía de allende el mar parecía ofrecer el placer del "descubrimiento" sorprendente de aspectos subyacentes a la vida cotidiana ambiental, hasta este momento siempre hostilizados por la cultura oficial.

El inclusivismo defendido por Complexity and Contradiction (1966), según una postura intelectual desinhibida en la que el pasado se convierte en puro depósito de sugerencias formales a disposición del presente, vehiculaba un oportuno sentido de liberación de las restricciones disciplinares. Y durante estos años la obra del estudio PER estará cada vez más caracterizada por una tendencia irónica e inclusivista, mediante la estandarización de elementos cercanos al lenguaje figurativo del Pop, eludiendo la expresividad funcional y tecnológica recurrente en la arquitectura catalana contemporánea.

La gradual penetración de las ideas de Rossi y Venturi, pero también la presencia de Kahn, comportan el desmoronamiento del presunto

\footnotetext{
${ }^{4}$ Los subrayados son del original.
} 
monolitismo de épocas anteriores, ante el surgimiento de una multiplicidad de identidades connaturales a lo contemporáneo que además impiden destacar cualquier particularidad nacional; desvanecida la ilusión de poder cambiar la sociedad desde la arquitectura, la reflexión se dirige hacia itinerarios de rigurosa especificidad.

La fecha de 1975 (muerte del dictador e inicio de la transición democrática) no corresponde a ningún acontecimiento particularmente representativo en el mundo de la disciplina; sin embargo, muchas cosas habían ya sucedido o se estaban desarrollando, evidenciando una transformación repentina de las ideas y de los medios de comunicación. Termina así un período de "luchas" y comienza algo mucho más indiferenciado y menos aglutinador, totalmente diferente al pasado próximo en el que parecía que la arquitectura pudiese servir también para algo más que satisfacer unas estrictas instancias profesionales.

\section{Referências bibliográficas}

Bohigas, Oriol (1957), "Elogi de la barraca", in Barcelona entre el pla Cerdà i el barraquisme, Edicions 62, Barcelona, 1963 [2 $2^{\mathrm{a}} \mathrm{ed}$.].

Bohigas, Oriol (1960), "Elogi del totxo", in Barcelona entre el pla Cerdà i el barraquisme, Edicions 62, Barcelona, 1963 [2 $2^{a}$ ed.].

Bohigas, Oriol (1962), "Cap a una arquitectura realista”, Serra d'Or, 5, 18.

Bohigas, Oriol (1968), "Cantallops i Rodrigo, premi FAD”, Serra d'Or, 106, Barcelona, 50. Bohigas, Oriol (1969), “Una posible 'Escuela de Barcelona'”, Arquitectura, 118, 24-30. Bohigas, Oriol (1969a), "Casa para ricos", Destino, 13.

Bohigas, Oriol (1969b), Contra una arquitectura adjetivada. Barcelona: Ed. Seix Barral, 7-8.

Castellet, Josep Maria (1960), Veinte años de poesía española. Barcelona: Seix Barral. Clotet, Lluís (1970), "A Barcelona: por una arquitectura de la evocación", CAU, 2-3, 108. Jordá, Joaquim (1967), "La Escuela de Barcelona a través de Carlos Durán”, Nuestro Cine, 61, apud Esteve Riambau; Casimiro Torreiro (1999), La Escuela de Barcelona: el cine de la 'gauche divine'. Barcelona: Anagrama, 168-169.

Miserachs, Xavier (1998), Fulls de contactes. Memòries. Barcelona: Edicions 62.

Montalban, Manuel Vázquez (1970), "Racionalismo, arquitectura, butifarras y música dispersa”, Triunfo, 416, Barcelona, 23-5-1970, 16.

Montalban, Manuel Vázquez (1974), "La izquierda que nunca existió", Tele/eXpres, 25-5-1974, 13.

Moura, Beatriz de (1970), Carta para Oriol Bohigas, 25-1-1970. Archivo Bohigas.

Riera, Carme (1988), La Escuela de Barcelona. Barcelona: Ed. Anagrama.

Tusquets, Oscar (1967), "Sobre els premis F. A. D. 1966", Serra d'Or, 67. 